\title{
The Storage of Eggs.
}

MORE than four thousand million eggs are consumed in Great Britain during the course of a year; but this number would probably be increased if satisfactory methods of storing eggs produced at the glut period in the spring with the view of their consumption later in the year were generally introduced, especially as the producers would be encouraged to increase their stock, since the demand and the price fetched would show less marked fluctuations. But for a stored egg to be the equivalent of a new-laid egg in all respects requires considerable attention to detail: the factors on which good results depend are discussed by $\mathrm{T}$. Moran and J. Piqué in a recent publication of the Department of Scientific and Industrial Research. ${ }^{1}$

In the first place, only carefully selected eggs should be submitted to storage: they must be clean and should never have been exposed to a temperature greater than $60^{\circ} \mathrm{F}$., otherwise a certain amount of development of an egg, if fertile, may have occurred, resulting in its decomposition later in the store. The quality of an egg can be judged by its transparency to light, this process of examination being termed ' candling.' A new - laid egg appears clear and transparent, the yolk being vaguely seen as a rosytinted mass: the air chamber is small. As the egg ages it becomes less transparent, appearing slightly marbled; the yolk is movable along the long axis and the air chamber is larger. Bad eggs appear opaque on candling.

In the second place, attention must be paid to the method of packing when, as is most usual, the eggs are kept in the cold store ; the material used should be clean, odourless and moisture-proof, and the eggs should be so packed that a free circulation of air can occur around them. The temperature of the store should be maintained at $32-33^{\circ} \mathrm{F}$. and be kept as constant as possible: the humidity of the air should be about 80 per cent. : a higher humidity favours the growth of moulds, whilst a lower humidity increases the rate of evaporation of moisture from the eggs. Under the conditions specified the loss of weight of the stored eggs is about 2.68 per cent. over a period of seven months. A free air circulation is essential to keep them in good condition and prevent the growth of moulds. The authors consider in detail the various methods of packing eggs and of obtaining the requisite temperature and humidity in the storage chamber: they suggest that the loss

1 Department of Scientific and Industrial Research : Food Investigation. Special Report No. 26: The Storage of Eggs. By T. Moran and Is. $3 d$. net. of weight by evaporation may possibly be prevented by wrapping the eggs in waxed papers, although this would presumably increase their cost somewhat.

Certain changes occur in the eggs during cold storage: the white becomes more viscous, losing water both to the yolk and externally by evaporation the yolk membrane becomes more delicate, and when the egg is broken the yolk also is very liable to break, a familiar sign of age in an egg. Moreover, after about six months the eggs acquire an unpleasant taste from the packing material unless, as mentioned above, this is odourless and moisture-proof. The food value of stored eggs, however, is probably little inferior to that of new-laid: no loss of vitamin A has been detected even after long storage.

The removal of eggs from cold store requires care, since unless their temperature has risen to that of the outside air, moisture will be deposited on their surfaces, or they will 'sweat,' as it is called : and a damp egg does not fetch so good a price as a dry one. The process of 'defrosting' requires about twenty-four hours.

After a short account of the storage of eggs in water-glass or lime-water, T. Moran describes some experiments on the effects of low temperatures upon eggs. After freezing and thawing again, it is found that the liquid part of the white has increased and the viscous part decreased in amount, the extent of the change depending on the temperature reached and the time of exposure to that temperature. On the other hand, the yolk shows no change unless the temperature has fallen below $-6^{\circ} \mathrm{C}$., and unless freezing has actually occurred. If the egg is kept at this temperature for a sufficient length of time, on thawing the yolk is found to be in a stiff pasty condition; if the processes of freezing and thawing are carried out sufficiently rapidly this change does not occur. It appears to be due to a precipitation of lecitho-vitellin, so that re-solution does not occur on thawing: it is to be noted that simple freezing alone, at a temperature above $-6^{\circ} \mathrm{C}$., does not produce the change, so that it occurs at a time when the egg is frozen solid.

The effect of temperature on the life of the embryo was also studied. At $-6^{\circ}$ C. the embryo dies immediately: fertility is maintained longest at $8-\mathrm{ro}^{\circ} \mathrm{C}$., up to a maximum of about five weeks. The author points out in this connexion that the embryo is cold blooded up to about the twentieth day of development.

Apart from its scientific interest, the report merits the attention of all those engaged in the commercial production of eggs in Great Britain.

\section{Commonwealth Fund Fellowships.}

THE Committee of Award for the Commonwealth Fund Fellowships has made the following appointments to the twenty fellowships tenable by British graduates in American universities for the two years beginning in September I926:

Mr. A. M. Adamson, University of St. Andrews, to the University of California, in zoology; Mr. F. N. Astbury, University of Liverpool, to Columbia University, in architecture; Mr. I. W. M. A. Black, University of St. Andrews, to Yale University, in physical chemistry; Mr. F. P. Chambers, Clare College, University of Cambridge, to Harvard University, in architecture; Miss M. E. Cranswick, King's College, University of London, to Columbia University, in education; Mr. R. Fisher, Hertford
College, University of Oxford, to Yale University, in economics; Miss I. Gordon, University of Aberdeen and the Imperial College of Science and Technology, London, to Stanford University, in zoology; Miss H. A. C. Green, Westfield College, University of London, to the University of Pennsylvania, in literature; Mr. D. B. Harden, Trinity College, University of Cambridge, and the University of Aberdeen, to the University of Michigan, in archæology; Mr. R. L. Lechmere-Oertel, University of Birmingham, to Columbia University, in engineering ; Mr. K. A. H. Murray, University of Edinburgh, to Cornell University, in economics ; Mr. E. P. Mumford, University of Manchester and Christ's College, University of Cambridge, to the University of California, 